\title{
Fundamentals of POLYMER ENGINEERING
}




\section{Fundamentals of POLYMER ENGINEERING \\ Arie Ram TECHNION-ISRAEL INSTITUTE OF TECHNOLOGY HAIFA, ISRAEL}


Ram, Arie.

Fundamentals of polymer engineering / Arie Ram.

p. $c m$.

Includes bibliographical references and index.

ISBN 978-1-4899-1824-6

1. Polymers. I. Title.

TP1087.R36 1997

$668.9--d c 21$

97-41516

CIP

C 1997 Springer Science+Business Media New York Originally published by Plenum Press New York in 1997

Softcover reprint of the hardcover 1st edition 1997

All rights reserved

10987654321

No part of this book may be reproduced, stored in a retrieval system, or transmitted in any form or by' any means, electronic, mechanical, photocopying, microfilming, recording, or otherwise, without written permission from the Publisher

Book Designed by Reuven Solomon 
To my beloved wife SARA who patiently did the hard work on the hard disk 


\section{Preface}

We all are surrounded by plastic materials and cannot imagine modern life and utilities without the synthetic polymers. And yet, how many of us can distinguish between polyethylene and PVC? After all, most people name any polymer as "Nylon." Is there any distinction between polymers and plastics?

This introductory textbook tries to answer these questions and many others. It endeavors to provide the basic information required in modern life about the best utilization of new materials in the plastics era; the chemical sources of synthetic polymers, and the processes in which small "simple" molecules are converted to giant macromolecules, namely, high polymers; and the understanding of the role of these unique structures, their behavior and performance, their mechanical and thermal properties, flow and deformation.

As we are mainly interested in the final product, the processing of plastics, through shaping and forming, presents a significant challenge to polymer engineering. All this is broadly discussed, ending with modern issues like composites, ecology and future prediction, followed by up-to-date information and data about old as well as novel high performance polymers.

The text is particularly targeted towards senior students of science and engineering (chemical, material, mechanical and others) who may use it as the first window to the world of polymers. At the same time many professionals who are involved in the resin or plastics industry may prefer this approach without elaborate math or overloading.

This book is mainly based on thirty-five years of teaching polymer engineering at the Technion, Haifa, Israel, and several universities in the United States. 


\section{Acknowledgments}

\section{$I$ wOUlD LIKE TO acknowledge the Departments of Chemical}

Engineering at the Technion, Haifa, and UCLA, Los Angeles, for providing the facilities and environment for writing this textbook.

Many thanks are due to Sidney and Raymond Solomon, of the Solomon Press, and to Mary Russell who carried out the professional work of editing, design, layout and publishing, with great care and tolerance.

Last but not the least, I wish to thank my numerous students, from whom I learned the most. 


\section{Contents}

List of Photos xiv

List of Tables $\quad$ xv

List of Figures $\quad$ xvii

List of Symbols $\quad$ xxi

CHAPTER 1 INTRODUCTION TO THE WORLD OF POLYMERS 1

Problems 3

CHAPTER 2 THE CHEMISTRY OF POLYMERS 5

2.1 Introduction 5

2.2 The Petrochemical Industry 5

Monomers Derived from Ethylene $\quad 7$

Monomers Derived from Propylene $\quad 8$

Phenol and Other Aromatics 9

2.3 Monomers: Building Blocks for Polymer Manufacture $\quad 10$

2.4 Polymerization-The Mechanism of the Process 14

Chain (Addition) Polymerization 16

$\begin{array}{ll}\text { INITIATION } & 17\end{array}$

$\begin{array}{lr}\text { PROPAGATION } & 18\end{array}$

$\begin{array}{ll}\text { TERMINATION } & 18\end{array}$ 
TRANSFER REACTIONS

IONIC POLYMERIZATION

Stepwise Polymerization $\quad 23$

Copolymerization 25

2.5 Polymerization-Industrial Processes 28

Bulk Polymerization 28

Solution Polymerization $\quad 29$

Suspension Polymerization 29

Emulsion Polymerization $\quad 30$

Problems

CHAPTER 3 STRUCTURE AND CHARACTERIZATION OF POLYMERS

3.1 The Chemical Structure

3.2 The Molecular Architecture 34

3.3 Molecular Weights and Their Distribution 37

3.4 Transitions $\quad 44$

3.5 Morphology 49

Problems

CHAPTER 4 BEHAVIOR OF POLYMERS 58

4.1 Rheology of Polymers 58

4.2 Mechanical Properties of Polymers and Plastics 75

Characteristics of Typical Mechanical Properties $\quad 78$ RIGID AND BRITTLE $\quad 78$

RIGID AND STRONG $\quad 78$

RIGID AND TOUGH $\quad 78$

SOFT AND TOUGH $\quad 79$

Impact Strength $\quad 83$

Hardness, Abrasion and Friction $\quad 85$

4.3 Optical, Electrical, Thermal and Chemical Properties $\quad \mathbf{8 8}$ Optical Properties $\quad 88$

Electrical Properties 90

SPECIFIC VOLUME RESISTIVITY 90

DIELECTRIC CONSTANT AND LOSS FACTOR 91

DIELECTRIC STRENGTH

Thermal Properties 92

COEFFICIENT OF THERMAL EXPANSION 93

Chemical Properties 93

4.4 Structure-Property Relationship 96

$\begin{array}{ll}\text { 4.5 Summary } & 97\end{array}$

Problems 


\section{CHAPTER 5 COMPOUNDING AND PROCESSING}

OF PLASTICS 103

5.1 Additives for the Preparation of Plastic Materials 103 Stabilizers 104

Fillers and Reinforcement 106

Plasticizers 108

Colorants 108

Special Additives for the Improvement of Workability and Performance 109

5.2 Extrusion of Thermoplastics 111

Drag Flow, $q_{d} \quad 115$

Pressure Flow, $q_{p} \quad 115$

Leakage Flow, $q_{e} \quad 116$

5.3 Injection Molding 125

5.4 Blow and Rotational Molding, Thermal Forming and Calendering

Blow Molding

Rotational Molding 136

Thermoforming and Vacuum Forming 136

Calendering

138

Other Fabrication Methods 139

CASTING

139

COLD FORMING 139

FOAMING

Compression Molding 141

Transfer Molding

5.6 Processing of Reinforced Materials 142

5.7 Welding and Bonding 143

WELDING BY HOT GAS 143

WELDING BY A HOT PLATE 143

ULTRASONIC WELDING $\quad 143$

WELDING BY FRICTION $\quad 144$

WELDING AT HIGH FREQUENCY 144

BONDING 144

5.8 Comparison among Various Processing Methods 144

Problems $\quad 145$

\section{CHAPTER 6 DESCRIPTION OF MAJOR PLASTICS:}

STRUCTURE, PROPERTIES AND

UTILIZATION

6.1 Information about Various Plastics $\quad 148$

Thermoplastics 
LOW DENSITY POLYETHYLENE (LDPE) 149

LINEAR LOW DENSITY POLYETHYLENE (LLDPE) 152

HIGH DENSITY POLYETHYLENE (HDPE) 153

POLYPROPYLENE (PP) 154

POLYBUTYLENE (POLYBUTENE-1) 155

POLYMETHYLPENTENE (TPX) 156

POLYVINYLCHLORIDE (PVC) 156

CHLORINATED POLYETHER (PENTON) 160

FLUOROCARBON POLYMERS (FLUOROPLASTICS) 160

POLYSTYRENE (PS) 162

ACRYLONITRILE-BUTADIENE-STYRENE (ABS) 164

$\begin{array}{ll}\text { ACRYLICS } & 165\end{array}$

ACETAL, (POLYACETAL) POLY-OXYMETHYLENE (POM) 166

POLYAMIDES (PA), NYLON 167

SATURATED POLYESTERS (PET, PBT) 171

POLYCARBONATE (PC) 172

POLYPHENYLENE-OXIDE (PPO, NORYL) 173

POLYSULFONES (PSU) 173

$\begin{array}{ll}\text { PHENOXY } & 174\end{array}$

$\begin{array}{ll}\text { POLYPHENYLENE-SULFIDE (PPS) } & 175\end{array}$

POLYIMIDES (PI), POLYAMIDE-IMIDE (PAI),

$\begin{array}{ll}\text { IONOMER } & 177\end{array}$

$\begin{array}{ll}\text { POLY-BENZIMIDAZOLE } & 177\end{array}$

$\begin{array}{ll}\text { POLY-PARA-XYLENE (Parylene) } & 178\end{array}$

$\begin{array}{ll}\text { POLYARYLATE (PAR) } & 178\end{array}$

POLYETHER-ETHERKETONE (PEEK) $\quad 178$

LIQUID CRYSTAL POLYMERS (LCP) 178

CELLULOSIC POLYMERS $\quad 179$

$\begin{array}{ll}\text { Thermosets } & 179\end{array}$

PHENOL-FORMALDEHYDE (PF) 180

UREA-FORMALDEHYDE (UF, 1928), MELAMINE-
FORMALDEHYDE (MF, 1939)

UNSATURATED POLYESTER (UPES) 182

EPOXY RESINS (EP) 183

POLYURETHANE (PUR) $\quad 184$

SILICONES (SI) 185

ALLYL, POLY-DIALLYL-PHTHALATE (PDAP) 186

FURAN 186

$\begin{array}{lr}\text { 6.2 Special Uses } & 186\end{array}$

$\begin{array}{lr}\text { Synthetic Elastomers } & 187\end{array}$

Synthetic Fibers $\quad 188$

Synthetic Coatings and Paints 189

Synthetic Adhesives 191

USES IN CONSTRUCTION 192

USES IN PACKAGING 194 
USES IN TRANSPORTATION

196

USES IN MEDICINE

6.3 Polyblends and Alloys

6.5 Future of the Plastics Industry

CHAPTER 7 PLASTICS AND ECOLOGY

7.1 Reuse, Reduce, Replace

7.2 Recovery and Recycling

218

Primary Recycling

218

Secondary Recycling

219

7.3 Tertiary Recycling

222

7.4 Energy Recovery-Incineration

223

7.5 Bio- and Photodegradation

224

7.6 Technology of Recycling

225

Problems 


\section{List of Photos}

\section{CHAPTER FIVE}

5-1 Section view of a single screw plastics extruder 112

5-2 An injection molding machine

\section{CHAPTER SIX}

Unnumbered There is a wide world of plastics- 


\section{List of Tables}

TABLE

NUMBER

TITLE

PAGE

1-1 Historical Development of Synthetic Polymers

2-1 Monomers Polymerized by Addition

12

2-2 Monomers Reacting by Stepwise Polymerization

2-3 Initiation in Chain Polymerization

2-4 Methods of Industrial Polymerization

3-1 Transition Temperatures of Some Polymers

4-1 Relative Specific Tensile Strength

4-2 Polymer Structure-Property Relationship

5-1 Comparison among Major Processing Operations

6-1 Structure of Commercial Nylons

6-2 Consumption of Synthetic Fibers

6-3 Use of Plastics in Construction

6-4 Use of Plastics in Transportation 
TABLE

6-5 Properties and Utilities of Selected Polymers

6-6 Mechanical Properties of Useful Polymers

6-7 Thermal, Electrical and General Properties of Useful Polymers

6-8 Consumption and Relative Prices of Commercial Polymers

6-9 Physical Properties and Consumption of High Performance Polymers (United States, 1993)

6-10 Global Consumption of Polymers, 1994

7-1 Comparison of Energy Cost of Manufacture for Disposable and Returnable Milk Containers

7-2 Breakdown of Typical Domestic Wastes in the United States around 1990

7-3 Breakdown of Polymers Used in Packaging

7-4 Utilization of Plastics (United States, 1990)

7-5 Caloric Value of Plastics and Other Materials 


\section{List of Figures}

FIGURE

NUMBER

TITLE

PAGE

2-1 Equilibrium curve for copolymerization

3-1 Polymer chain dimensions

3-2 Steric structure of chains

3-3 A zigzag structure of PE

3-4 A differential MWD curve

3-5 Osmotic pressure of polymer solutions

3-6 Separation in GPC columns

3-7 Universal calibration curve for GPC measurements

3-8 Transition temperatures

3-9 Multiple transitions

3-10 Changes in modulus around $T_{g}$

3-11 Morphology of polymer chains

3-12 Morphology of crystallites from polymer melts

3-13 Kinetics of crystallization 
4-1 Shear stresses and deformation

4-2 Flow curves of various liquids

4-3 Apparent viscosity of various liquids

4-4 Dependence of melt viscosity on MW 61

4-5 Ferry's equation 63

4-6 Carreau's equation 63

4-7 Mechanical models for solids (spring) and liquids (dash-pot)

4-8 Deformation of an elastic solid (at constant stress)

4-9 Deformation of a Newtonian liquid (at constant stress)

4-10 A Maxwell model

4-11 Deformation of the Maxwell model

4-12 Stress relaxation of a Maxwell model 67

4-13 A Voigt (Kelvin) model 68

4-14 Deformation of a Voigt body 68

4-15 The Burger model 69

4-16 Deformation of Burger body 70

4-17 Time (or temperature) dependence of relaxation modulus

4-18 A master curve (at $25^{\circ} \mathrm{C}$ ) for generalized amorphous polymer

4-19 The complex modulus

4-20 Frequency dependence of storage modulus 73

4-21 The electronic Maxwell body 74

4-22 The electronic Voigt body $\quad 74$

4-23 A stress-strain curve 75

4-24 Stress-strain curves at various temperatures 76

4-25 A stress testing dumbbell

4-26 Necking of a dumbbell 77 
FIGURE

NUMBER

TITLE

PAGE

4-27 Stress-strain graph of a rigid and brittle material 78

4-28 Stress-strain graph of a rigid and strong material 78

4-29 Stress-strain graph of a rigid and tough material 79

4-30 Stress-strain graph of a soft and tough material 79

4-31 Performance of elastomers

4-32 Effect of orientation on tensile strength 8

$\begin{array}{lll}\text { 4-33 Flexure test } & 82\end{array}$

4-34 Decrease of tensile strength with time 83

4-35 A specimen for impact test 84

4-36 Creep tests 86

4-37 Creep and stress relaxation profiles (three-dimensional)

4-38 Fatigue test

4-39 Complex dielectric constant in alternating current

5-1 A single screw extruder (schematic)

5-2 Various types of screws

5-3 A scheme of the channel

5-4 Velocity profile of drag flow

5-5 Velocity profile of pressure flow

5-6 Velocity profile for $a=1$

5-7 Velocity profile for $a=1 / 3 \quad 118$

5-8 Operating lines of the screw 119

5-9 Operating lines for the screw and the die 120

5-10 Dependence of output on velocity at isothermal conditions

5-11 Operating lines at various temperatures

5-12 Operating curves for non-Newtonian liquids

5-13 The layout of an injection molding apparatus 126

5-14 History of pressure in the mold cycle 
[ $\mathrm{xx}$ ] List of Figures

FIGURE

NUMBER

TITLE

PAGE

5-15 Field of workability in injection molding

5-16 The principle of blow molding

135

5-17 The process of extrusion film blowing

5-18 Scheme of vacuum forming operation

5-19 Principle of calendering 


\section{List of Symbols}

\section{SYMBOL DEFINITION}

a exponent in eq. 3-5

A area

AO antioxidant

b width

B second virial coefficient (eqs. 3-11, 3-12)

C concentration

CAD computer aided design

CAM computer aided manufacture

Cp specific heat

d thickness; diameter; density

D diameter; diffusivity

De Deborah number

DP degree of polymerization (number of mers)

DSC differential scanning calorimetry

E energy of activation; Young's modulus; electrical potential

ESC environomental stress cracking 
initiator efficiency (eq. 2-42)

mole fraction of component $i$ in feed mixture (for copolymerization)

F force

$F_{i} \quad$ mole fraction of component $i$ in copolymer chain

G shear modulus

$\mathrm{G}^{\prime} \quad$ storage modulus

G" loss modulus

$\mathrm{G}^{\star} \quad$ complex modulus

GPC gel permeation chromatography

$\mathrm{h}$

depth of screw channel (extruder)

$\mathrm{H} \quad$ optical constant (eq. 3-12)

initiator concentration; current (electrical)

J

compliance

k kinetic constant; heat conduction coefficient

$k_{d}$ initiator decomposition rate constant

$\mathbf{k}_{\mathrm{i}}$ rate constant of initiation rate constant of propagation; rate constant of polymerization

$\mathbf{k}_{\mathrm{t}}$ rate constant of termination

$\mathbf{k}_{\mathrm{t}, \mathrm{c}}$ rate constant of termination via combination

$\mathbf{k}_{\mathrm{t}, \mathrm{d}}$ rate constant of termination via disproportionation rate of constant for transfer length

L length

LCP liquid crystal polymer monomer concentration

$\mathrm{M}_{\mathrm{o}} \quad$ monomer molecular weight

$M^{\star} \quad$ monomer radical concentration

$\overline{\mathrm{M}}_{\mathrm{n}} \quad$ number-average molecular weight

$\overline{\mathrm{M}}_{\mathrm{v}} \quad$ viscosity-average molecular weight

$\bar{M}_{\mathrm{w}} \quad$ weight-average molecular weight

$\overline{\mathrm{M}}_{\mathrm{z}} \quad \mathrm{z}$ average molecular weight 


$\begin{array}{ll}\bar{M}_{z+1} & z+1 \text { average molecular weight } \\ \text { MFI } & \text { melt flow index } \\ \text { MSW } & \text { municipal solid waste } \\ \text { MW } & \text { molecular weight } \\ \text { MWD } & \text { molecular weight distribution }\end{array}$

$\mathrm{n} \quad$ number of moles; number of repeating units (mers); exponent in eq. 3-15 (Avrami); exponent in power law (eq. 4-3) number of functional groups (in condensation), speed of rotation

$\mathrm{N}_{\mathrm{o}} \quad$ initial number of functional groups

$\mathrm{P}$ polymer concentration; pressure; load; permeability; degree of conversion

ppb parts per billion

ppm parts per million

$\mathrm{q}_{d} \quad$ drag flow rate

$\mathrm{q}_{r} \quad$ leakage flow rate

$\mathrm{q}_{\mathrm{p}} \quad$ pressure flow rate

Q flow rate (volumetric); electrical charge

$r_{i} \quad$ rate of initiation

$r_{p} \quad$ rate of propagation; rate of polymerization

$r_{t} \quad$ rate of termination

R gas constant; end-to-end distance; electrical resistivity

$\mathrm{R}^{*} \quad$ primary radical concentration

RIM reactive injection concentration

S

tensile strength; solubility

$S_{B} \quad$ tensile strength at break

$\mathrm{S}_{\mathrm{y}} \quad$ tensile strength at yield

t time; thickness; pitch (extruder)

$t_{c} \quad$ cooling time (injection molding)

$t_{\mathrm{f}} \quad$ filling time (injection molding)

$t_{n} \quad$ "dead" time (injection molding)

$t_{s} \quad$ cycle time (injection molding) 
[ xxiv ] List of Symbols

\begin{tabular}{ll}
$T$ & temperature \\
$T_{c}$ & temperature of crystallization \\
$T_{d}$ & heat distortion temperature \\
$T_{f}$ & temperature at opening of the mold \\
$T_{g}$ & glass transition temperature \\
$T_{i}$ & temperature of injection \\
$T_{m}$ & melting temperature \\
$T_{s}$ & surface temperature (mold) \\
$\mathrm{u}$ & velocity \\
$\mathrm{U}$ & velocity \\
$\mathrm{UHMW}$ & ultra high MW \\
$\mathrm{UV}$ & ultraviolet \\
$\mathrm{UVA}$ & ultraviolet absorber \\
$\mathrm{V}$ & velocity; volume; specific volume; elution volume \\
$\mathrm{V}_{\mathrm{a}}$ & specific volume of amorphous phase \\
$\mathrm{V}_{\mathrm{c}}$ & specific volume of crystalline phase \\
$\mathrm{w}_{\mathrm{i}}$ & weight fraction of species i \\
$\mathrm{W}$ & weight \\
$\mathrm{W}_{\mathrm{i}}$ & weight fraction \\
$\mathrm{x}_{\mathrm{i}}$ & mole fraction of species i \\
$\mathrm{X}$ & mole ratio in the feed (copolymerization) \\
$\mathrm{Y}$ & mole ratio in the copolymer chain \\
& \\
\hline
\end{tabular}

\section{Greek Symbols}

\section{SYMBOL DEFINITION}

$\alpha$

$\gamma$

$\dot{\gamma}$

$\delta$

$\epsilon$

$\eta$ thermal expansion coefficient; heat diffusivity

strain; surface energy

rate of shear (velocity gradient)

shift angle; depth of deformation

dielectric constant

viscosity 


\begin{tabular}{ll}
$\eta_{\mathrm{o}}$ & low-shear viscosity (Newtonian) \\
$\eta_{\mathrm{Tg}}$ & viscosity at $\mathrm{T}_{\mathrm{g}}$ \\
$\theta$ & dimensionless temperature, shift angle \\
$\lambda$ & relaxation time, retardation time \\
$\mu$ & viscosity (Newtonian); micron \\
$\mu_{\mathrm{e}}$ & effective viscosity \\
$\mu_{\mathrm{r}}$ & relative viscosity \\
$\mu_{\mathrm{s}}$ & viscosity of solvent \\
$\mu_{\mathrm{sp}}$ & specific viscosity \\
{$[\mu]$} & intrinsic viscosity \\
$\nu$ & Poisson ratio \\
$\pi$ & osmotic pressure \\
$\Pi$ & power \\
$\rho$ & resistivity (electrical); density \\
$\tau$ & turbidity; shear stress \\
$\phi$ & angle of inclination (extruder screw) \\
$\omega$ & shift angle \\
& frequency \\
\hline &
\end{tabular}

